\title{
Non-invasive duo positive airway pressure ventilation versus nasal continuous positive airway pressure in preterm infants with respiratory distress syndrome: a randomized controlled trial
}

\author{
Arash Malakian ${ }^{1}$, Mohammad Reza Aramesh ${ }^{1}$, Mina Agahin ${ }^{1}$ and Masoud Dehdashtian ${ }^{1,2^{*}}$ (DD
}

\begin{abstract}
Background: The most common cause of respiratory failure in premature infants is respiratory distress syndrome. Historically, respiratory distress syndrome has been treated by intratracheal surfactant injection followed by mechanical ventilation. In view of the risk of pulmonary injury associated with mechanical ventilation and subsequent chronic pulmonary lung disease, less invasive treatment modalities have been suggested to reduce pulmonary complications.

Methods: 148 neonates (with gestational age of 28 to 34 weeks) with respiratory distress syndrome admitted to Imam Khomeini Hospital in Ahwaz in 2018 were enrolled in this clinical trial study. 74 neonates were assigned to duo positive airway pressure (NDUOPAP) group and 74 neonates to nasal continuous positive airway pressure (NCPAP) group. The primary outcome in this study was failure of N-DUOPAP and NCPAP treatments within the first $72 \mathrm{~h}$ after birth and secondary outcomes included treatment complications.

Results: there was not significant difference between DUOPAP (4.1\%) and NCPAP (8.1\%) in treatment failure at the first $72 \mathrm{~h}$ of birth $(p=0.494)$, but non-invasive ventilation time was less in the DUOPAP group $(p=0.004)$. There were not significant differences in the frequency of patent ductus arteriosus (PDA), pneumothorax, intraventricular hemorrhage (IVH) and bronchopulmonary dysplasia (BPD), apnea and mortality between the two groups. Need for repeated doses of surfactant $(p=0.042)$ in the NDUOPAP group was significantly lower than that of the NCPAP group. The duration of oxygen therapy in the NDUOPAP group was significantly lower than that of the NCPAP group ( $p=0.034$ ). Also, the duration of hospitalization in the NDUOPAP group was shorter than that of the NCPAP group $(p=0.002)$.

Conclusions: In the present study, DUOPAP compared to NCPAP did not reduce the need for mechanical ventilation during the first $72 \mathrm{~h}$ of birth, but the duration of non-invasive ventilation and oxygen demand, the need for multiple doses of surfactant and length of stay in the DUOPAP group were less than those in the CPAP group.
\end{abstract}

\footnotetext{
*Correspondence: dehdashtian@ajums.ac.ir; m.dehdashtian@gmail.com

'Department of Pediatrics, Imam Khomeini Hospital, Ahvaz Jundishapur

University of Medical sciences, Ahvaz, Iran

${ }^{2}$ Department of Paediatrics, Ahvaz Jundishapur University of Medical

Sciences, Ahvaz, Iran
}

(c) The Author(s). 2021 Open Access This article is licensed under a Creative Commons Attribution 4.0 International License, which permits use, sharing, adaptation, distribution and reproduction in any medium or format, as long as you give appropriate credit to the original author(s) and the source, provide a link to the Creative Commons licence, and indicate if changes were made. The images or other third party material in this article are included in the article's Creative Commons licence, unless indicated otherwise in a credit line to the material. If material is not included in the article's Creative Commons licence and your intended use is not permitted by statutory regulation or exceeds the permitted use, you will need to obtain permission directly from the copyright holder. To view a copy of this licence, visit http://creativecommons.org/licenses/by/4.0/ The Creative Commons Public Domain Dedication waiver (http://creativecommons.org/publicdomain/zero/1.0/) applies to the data made available in this article, unless otherwise stated in a credit line to the data. 
Trial registration: IRCT20180821040847N1, Approved on 2018-09-10.

Keywords: Duo positive airway pressure, Nasal continuous positive airway pressure, Preterm infants, Respiratory distress syndrome

\section{Background}

Respiratory insufficiency is a common problem in term infants and preterm neonates in neonatal intensive care units. In premature infants, the most common cause of respiratory failure is respiratory distress syndrome (RDS) [1]. RDS remains the leading cause of adverse events and mortality in premature infants, affecting approximately $26 \%$ of infants born between 32 and 34 weeks of gestation [2].

Historically RDS has been treated by injection of surfactant into the trachea followed by mechanical ventilation. Because of the risk of pulmonary injury associated with mechanical ventilation, followed by the development of chronic lung disease and other complications including subglottic stenosis and pneumonia, less invasive therapies have been proposed to reduce pulmonary complications [3].

In recent years, studies have focused on non-invasive ventilation techniques to reduce the need for mechanical ventilation and its associated pulmonary complications [4]. There are currently a number of non-invasive respiratory care options for preterm infants, including nasal continuous positive airway pressure (NCPAP), nasal intermittent positive ventilation (NIPPV), nasal high frequency oscillation (NHFO) and high flow nasal cannula (HFNC) [5].

One of the common clinical strategies is the use of NCPAP, which has been shown to be effective in reducing ventilation through endotracheal tube and chronic pulmonary disease in very preterm infants $[6,7]$. However, in randomized clinical trials, some patients undergoing NCPAP still required intubation due to worsening of patients' clinical status $[8,9]$, because NCPAP does not necessarily improve alveolar ventilation or $\mathrm{CO}_{2}$ elimination [10].

Currently, NCPAP is the standard treatment for respiratory distress syndrome (RDS) [11]. Duo positive airway pressure (DUOPAP) is a new respiratory support mode consisting of a combination of two CPAP levels. In fact, DUOPAP mode is same as bilevel positive airway pressure (BIPAP). In the DUOPAP mode, PDuo is the maximum pressure that is alternately applied to the previous baseline CPAP. Breathing rate is the number of PDuo applied per minute [12]. DUOPAP respiratory support increases mean airway pressure, tidal volume and minute ventilation and subsequently improves hypoxia and $\mathrm{CO}_{2}$ retention [12].
In this study, it is hypothesized that early use of NDUOPAP reduces the need for invasive respiratory support compared to NCPAP in preterm infants with respiratory distress syndrome.

\section{Methods}

This study was performed in a Neonatal Intensive Care Unit at Imam Khomeini Hospital of Ahvaz Jundishapur University of Medical Sciences in Ahvaz, Iran, during 2018-2019. Premature infants with gestational age of 28 to 34 weeks who had respiratory distress syndrome and their respiratory distress score based on the SilvermanAnderson table was 6 and 7 during the first $6 \mathrm{~h}$ of birth were enrolled [13-16].

Exclusion criteria included presence of major anomalies, airway anomaly, severe cardiovascular instability, respiratory distress secondary to severe asphyxia (Apgar score $\leq 3$ at 1 and 5 min and umbilical cord blood $\mathrm{pH}<$ 7.1), parental discontent, gestational age less than 28 weeks, cyanotic heart disease, meconium aspiration syndrome, diaphragmatic hernia, invasive mechanical ventilation started from the beginning of hospitalization, pulmonary hemorrhage, lack of effective spontaneous breathing, metabolic disease during hospitalization and respiratory problems due to neuromuscular diseases and sepsis [12-16].

All parents were required to complete and write an informed consent form before the neonates were enrolled in the study, according to the Ethics Committee of Jundishapur University of Medical Sciences (IR.AJUMS.REC.1397.365). Also, the present study was registered in the Iranian Clinical Trial Documentation Office on 10.9.2018 (IRCT: 2,018,082 1040847NI).

In this unmasked randomized trial, neonates were randomly divided into two groups of NDUOPAP and NCPAP.NDUOPAP group was considered group A and NCPAP group as group B. Based on the https://www. Sealedenvelope.com/simple-randomizer/V1/lists, the list was prepared. Six blocks were initially considered, including $\mathrm{AABB}, \mathrm{ABAB}, \mathrm{ABBA}, \mathrm{BABA}, \mathrm{BAAB}, \mathrm{BBAA}$ and each block was assigned a code between 1 and 6 . The statistical consultant randomly selected a number from 1 to 6 to create a random sequence and as a result, the infants were randomized into the two groups of A and B. Sample size was calculated by formula and according to the sample size of Zhou et al. [12] article, where the failure rates of non-invasive NDUOPAP and NCPAP 
treatment were 4.44 and $22.5 \%$, respectively, 67 patients were studied in each group. Due to the probability of at least $10 \%$ sample attrition, 7 individuals were added to each group, resulting in a sample size of 148 (74 subjects per group). After birth, the necessary resuscitation procedures were performed by a trained resuscitation team and a senior physician assistant for all infants who weighed below $1500 \mathrm{~g}$ according to the NICU protocol and infants were transited to NICU in presence of a specialized NICU nurse under T-piece respiratory support (Fisher \& paykel Healthcare, New Zealand) [16].

In the NICU, infants who were eligible for inclusion were randomly assigned to one of NDUOPAP or NCPAP groups. In infants of the DUOPAP group Fabian device (Acutronic, Switzerland, Infant flow driver) was used, which was connected to the infant via standard nasal tubes and injectors through a nasal prong. For neonates in this group, baseline parameters including PDuo $\left(8 \mathrm{~cm} \mathrm{H}_{2} \mathrm{O}\right)$ and CPAP $\left(5 \mathrm{~cm} \mathrm{H}_{2} \mathrm{O}\right), \mathrm{FIO}_{2} 40 \%$, inhalation time of $0.5 \mathrm{~s}$, and respiratory rate between 30 and 40 breaths per minute were adjusted. Based on clinical examination, arterial blood gas (ABG) and $\mathrm{SPO}_{2}$, device parameters were changed. The highest acceptable CPAP and PDuo levels were less than $8 \mathrm{~cm} \mathrm{H}_{2} \mathrm{O}$ and $15 \mathrm{~cm} \mathrm{H}_{2} \mathrm{O}$, respectively, and the maximum $\mathrm{FIO}_{2}$ acceptable to continue treatment was $60 \%$. The goal of altering device setting was reaching $\mathrm{SPO}_{2}$ above $90 \%$ in the right hand, $\mathrm{PaO}_{2}$ above $50 \mathrm{mmHg}, \mathrm{PaCO}_{2}$ less than $50 \mathrm{mmHg}, \mathrm{pH}$ above 7.25 and lack of respiratory distress on physical examination $[12,13]$.

In the NCPAP group, infants were subjected to Fabian device (Acutronic, Switzerland, Infant flow driver). The device was connected to the infant by standard injectors and tubes through the nasal prong. In the NCPAP group the initial parameters of the device were CPAP $(5 \mathrm{~cm}$ $\mathrm{H}_{2} \mathrm{O}$ ) and $\mathrm{FIO}_{2} 40 \%$ and based on clinical examination, $\mathrm{ABG}$ and $\mathrm{SPO}_{2}$ changes of device parameters were performed. The highest acceptable CPAP level was less than or equal to $8 \mathrm{~cm} \mathrm{H}_{2} \mathrm{O}$ and the maximum $\mathrm{FIO}_{2}$ acceptable to continue treatment was $60 \%$. The target was $\mathrm{O}_{2}$ saturation above $90 \%$ in the right hand $\left(\mathrm{PaO}_{2} \geq 50 \mathrm{~cm} \mathrm{H} \mathrm{H}_{2} \mathrm{O}, \mathrm{PaCO}_{2}<50 \mathrm{~cm} \mathrm{H} \mathrm{H}_{2} \mathrm{O}\right.$, and $\mathrm{pH} \geq$ 7.25) and the absence of respiratory distress on physical examination [12, 13].

In both groups, based on existing therapeutic guides and under the direct supervision of the researcher, infants requiring $\mathrm{FIO}_{2}$ over $40 \%$ with $\mathrm{CPAP}>5 \mathrm{~cm}$ $\mathrm{H}_{2} \mathrm{O}$ to maintain $\mathrm{O}_{2}$ saturation in the right hand between 90 and $95 \%, 100 \mathrm{mg} / \mathrm{kg}$ surfactant (Survanta) were administered using the INSURE (Intubation, Surfactant and Extubation) method by a skilled practitioner who had been predetermined [17]. After INSURE, the infant received the same non-invasive ventilation used before INSURE.
A feeding tube was inserted to remove air from the baby's stomach. $\mathrm{O}_{2}$ saturation was monitored and recorded by pulse oximeter and respiratory rate, heart rate was monitored continuously, and blood pressure every $2 \mathrm{~h}$. In infants requiring a $\mathrm{FIO}_{2}$ greater than $40 \%$ to maintain $\mathrm{SPO}_{2}$ within the acceptable range (90-95\%), surfactant was re-administered after $6 \mathrm{~h}$ after the last surfactant administration and as needed for a full course of treatment (maximum of 4 doses).

ABG was measured on admission (all subjects), in cases in need of intervention, one hour after the intervention as well as every $12 \mathrm{~h}$ thereafter, and before and after surfactant administration and the results were recorded in a special form. Based on the results an appropriate intervention was carried out when necessary $[12,16,18,19]$. Occurrence of treatment failure as well as duration of intervention, pneumothorax, BPD, PDA, apnea, occurrence of death, IVH, duration of oxygen therapy, length of hospital stays and mean airway pressure were recorded every $6 \mathrm{~h}$ in each group. As decided, after improvement in patient's condition and $\mathrm{O}_{2}$ saturation maintenance for $6 \mathrm{~h}$, we went on to reduce the device settings, such that if in DUOPAP $\mathrm{FIO}_{2}$ was less than $30 \%$ and CPAP and PDuo were less than or equal to $3 \mathrm{~cm}$ of water and $5 \mathrm{~cm}$ of water, respectively, and the infant was breathing continuously and ABG was normal for $24 \mathrm{~h}$, the infant was disconnected from the apparatus and placed under oxyhood inhaling a mixture of air and oxygen with $\mathrm{FIO}_{2} 30-40 \%$ and a flow of 5 to $10 \mathrm{~L}$ per minute depending on the size of the hood and patient's $\mathrm{O}_{2}$ saturation [12].

In the CPAP group if the neonate was clinically stable (defined as respiratory rate lower than 60 per minute, no apnea and $\mathrm{O}_{2}$ saturation $>90 \%$ 0n right hand) parameters were reduced to: $\mathrm{CPAP} \leq 3 \mathrm{~cm} \mathrm{H}_{2} \mathrm{O}$ and $\mathrm{FIO}_{2}<$ $30 \%$. If neonate condition was stable for the preceding $24 \mathrm{~h}$, the neonate was separated from CPAP [12].

All of the participants received antibiotics, caffeine as prophylaxis for apnea of prematurity and appropriate fluid and electrolyte solutions.

The primary outcome was the need for endotracheal intubation within the first $72 \mathrm{~h}$ of treatment. Treatment failure criteria included at least one of the following: $\mathrm{pH}<7.2, \mathrm{PaCO}_{2}>60 \mathrm{mmHg}, \mathrm{PaO} 2<50 \mathrm{mmHg}$ with $\mathrm{FIO}_{2}>60 \%$, CPAP $>8 \mathrm{~cm} \mathrm{H} \mathrm{H}_{2} \mathrm{O}$ in NCPAP group and PDuo > $15 \mathrm{~cm} \mathrm{H}_{2} \mathrm{O}, \mathrm{CPAP}>8 \mathrm{~cm} \mathrm{H}_{2} \mathrm{O}$, and $\mathrm{FIO} 2>60 \%$ in NDUOPAP group or worsening of the clinical condition (increased respiratory distress due to severe retraction) or prolonged apnea (stopping breathing for more than $20 \mathrm{~s}$ ) or recurring apnea more than 2 times in $24 \mathrm{~h}$ with cyanosis and bradycardia ( $\mathrm{PR} \leq 100 / \mathrm{min})$ requiring ventilation with a bag and mask $[12,13,20]$.

Secondary outcomes included duration of non-invasive ventilation, duration of oxygen therapy, duration of 
hospitalization, occurrence of IVH, pneumothorax, BPD, PDA, apnea, and death. All patients underwent echocardiogram within $48 \mathrm{~h}$ of birth and afterward if needed. Brain ultrasonography for diagnosing IVH was performed on the third and seventh days. Pneumothorax was diagnosed on the basis of chest $\mathrm{x}$-ray and transillumination [11].

\section{Statistical analysis}

In quantitative variables mean and standard deviation were used to describe the data in addition to median and interquartile range. Frequency and percentage were used to describe the data. Normality of the data was analyzed using Kolmogorov-Smirnov test and Q-Q chart. Data were analyzed using chi-square, Fisher's exact test, t-test and Mann-Whitney test. Significance level was set at $P$-value less than 0.05 . All analyses were performed using SPSS version 22.

\section{Results}

According to Fig. 1, the study population consisted of 160 neonates born between 28 and 34 weeks of gestation with a diagnosis of RDS. A total of 12 neonates were excluded: 10 due to not meeting the inclusion criteria and 2 due to non-cooperation. Therefore, this study was performed on 148 infants, 74 treated with NCPAP and 74 treated with NDOUPAP.
The social and demographic characteristics of the infants are presented in Table 1 . There were no significant differences in baseline characteristic. The level of arterial $\mathrm{PCO}_{2}$ one hour after inclusion in the NDUOPAP group $\left(\mathrm{PaCO}_{2}: 44.06 \mathrm{mmHg}\right.$ ) was significantly lower than that of NCPAP $\left(\mathrm{PaCO}_{2}: 46.51 \mathrm{mmHg}\right)$ and this difference was significant $(p=0.029)$. Arterial $\mathrm{PO}_{2}$ level was higher one hour after start of treatment in the NDUOPAP group $(72.21 \mathrm{mmHg})$ than NCPAP $(67.01 \mathrm{mmHg})(p<0.001)$.

There was no significant difference in the primary outcome of treatment failure during the first $72 \mathrm{~h}$ of birth between the NDUOPAP $(3[4.1 \%])$ and NCPAP $(6[8.1 \%])$ groups $(p=0.494)$; Table 2 .

The duration of non-invasive ventilation was shorter in the NDUOPAP group and this difference was significant $(\mathrm{CPAP}=50.12 \pm 23.83 \mathrm{~h}$ vs. $\mathrm{DUOPAP}=39.18 \pm$ 18.14 h; $p=0.004$ ); Table 2.

The duration of oxygen therapy in the NDUOPAP group was shorter than that of NCPAP group $(\mathrm{CPAP}=$ 107.45 vs. DUOPAP $=75.48 ; p=0.034$;) Table 2 .

Duration of hospitalization in the NDUOPAP group was shorter than that of NCPAP $(\mathrm{CPAP}=668.08 \mathrm{~h}$ vs. DUOPAP $=495.88 \mathrm{~h} ; p=0.02$ ) Table 2.

Other outcomes including IVH, pneumothorax, BPD, PDA, apnea and death were not significantly different $(p>0.05)$; Table 2.

The mean airway pressure level in the NDUOPAP group was higher than that of the NCPAP group, but

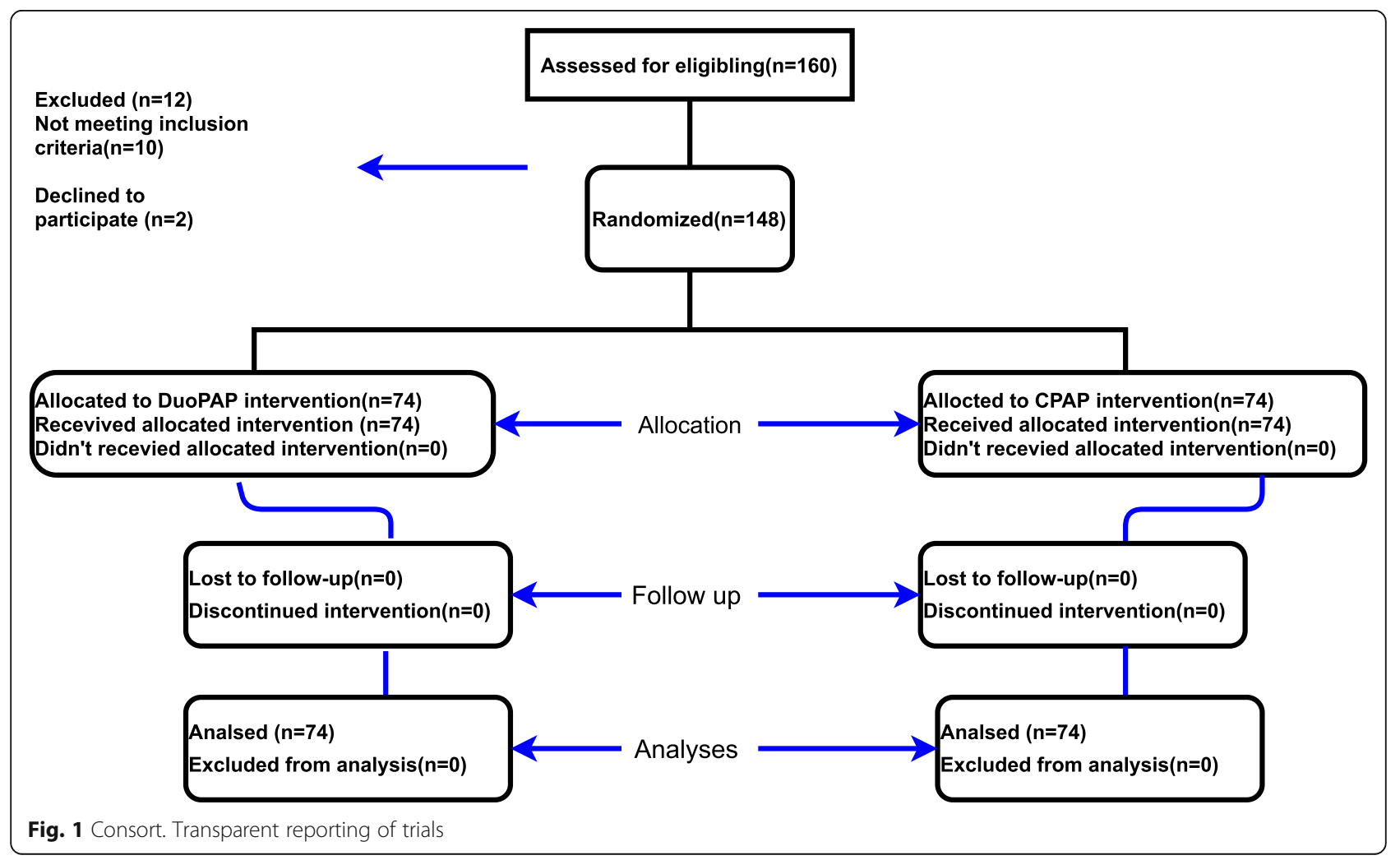


Table 1 Demographic and clinical Data in the study Groups

\begin{tabular}{|c|c|c|c|}
\hline Characteristic & DUOPAP & CPAP & $P$ value \\
\hline Male, n (\%) & $40(54.1 \%)$ & $32(43.2)$ & 0.188 \\
\hline Female, $n(\%)$ & $34(45.9 \%)$ & $42(56.8)$ & \\
\hline Cesarean delivery, $\mathrm{n}(\%)$ & $52(70.3 \%)$ & $57(77 \%)$ & 0.351 \\
\hline Vaginal delivery, n (\%) & $22(29.7 \%)$ & $17(23 \%)$ & \\
\hline Gestational age, weeks (mean \pm SD) & $31.32 \pm 1.53$ & $31.13 \pm 1.77$ & 0.618 \\
\hline Median (IQR) & $31.55(2.1)$ & $31.35(2.8)$ & \\
\hline Body weight, gr (mean \pm SD) & $1415 \pm 233.15$ & $1377.91 \pm 260.24$ & 0.357 \\
\hline Antenatal steroids, $\mathrm{n}(\%)$ First does & $70(94.6 \%)$ & $68(91.9 \%)$ & 0.798 \\
\hline Antenatal steroids, $\mathrm{n}(\%)$ second dose & $2(2.7 \%)$ & $3(4.1 \%)$ & \\
\hline Without Antenatal steroids, n (\%) & $2(2.7 \%)$ & $3(4.1 \%)$ & \\
\hline APGAR 1 min (mean+ SD) & $6.15 \pm 1.08$ & $6.08 \pm 0.89$ & 0.819 \\
\hline Median (IQR) & $6(2)$ & $6(2)$ & \\
\hline APGAR 5 min (mean \pm SD) & $7.69 \pm 0.79$ & $7.70 \pm 0 / 81$ & 0.928 \\
\hline Median (IQR) & $8(1)$ & $8(1)$ & \\
\hline PPROM, n (\%) & $12(17.6 \%)$ & $7(9.6 \%)$ & 0.161 \\
\hline $\begin{array}{l}\text { Age Mother, yrs. (mean } \pm \text { SD) } \\
\text { Mean IQR }\end{array}$ & $30.08 \pm 7.44$ & $29.24 \pm 6.59$ & 0.470 \\
\hline \multicolumn{4}{|l|}{ Gestational age group, n (\%) } \\
\hline 28-30 weeks & $12(16 \%)$ & $19(26 \%)$ & 0.879 \\
\hline $30-32$ weeks & $34(46 \%)$ & $23(31 \%)$ & \\
\hline 32-34 weeks & $28(38 \%)$ & $32(43 \%)$ & \\
\hline
\end{tabular}

$n$ number, SD Standard Deviation, IQR Inter Quartile Range

Table 2 Treatment effect and complication in study groups

\begin{tabular}{|c|c|c|c|}
\hline Characteristic & NDUOPAP & NCPAP & $P$ value \\
\hline Failure in first $72 \mathrm{~h}, \mathrm{n}(\%)$ & $3(4.1 \%)$ & $6(8.1 \%)$ & 0.494 \\
\hline $\begin{array}{l}\text { Duration of Noninvasive Respiratory support (hr) } \\
\text { (mean } \pm \text { SD) }\end{array}$ & $39.18 \pm 18.14$ & $50.12 \pm 23.83$ & 0.004 \\
\hline $\begin{array}{l}\text { Duration of oxygen therapy (hr) } \\
\text { (mean } \pm \text { SD) }\end{array}$ & $75.48 \pm 26.06$ & $107.45 \pm 156.06$ & 0.034 \\
\hline $\begin{array}{l}\text { Duration of hospitalization (hr) } \\
\text { Mean } \pm \text { SD) }\end{array}$ & $495.88 \pm 310.11$ & $668.08 \pm 360.46$ & 0.002 \\
\hline Pneumothorax, n median (IQR) & $0(0)$ & $2(2.7)$ & 0.497 \\
\hline $\begin{array}{l}\text { IVH, n (\%) } \\
\text { Grade I \& II }\end{array}$ & $3(4.1)$ & $5(6.8)$ & 0.719 \\
\hline PDA mild, n (\%) & $4(5.4 \%)$ & $5(6.8 \%)$ & 1 \\
\hline PDA moderate, $n$ (\%) & $4(5.4)$ & $3(4.1)$ & 1 \\
\hline BPD, n (\%) & $0(0)$ & $1(1.4)$ & 0.319 \\
\hline Apnea, n (\%) & $1(1.4 \%)$ & $4(5.4 \%)$ & 0.366 \\
\hline Deaths, n (\%) & $2(2.7 \%)$ & $5(6.8 \%)$ & 0.442 \\
\hline $\begin{array}{l}\text { Surfactant } \\
\text { First dose, } \mathrm{n}(\%)\end{array}$ & $31(41.9 \%)$ & $39(52.7 \%)$ & 0.042 \\
\hline $\begin{array}{l}\text { Surfactant } \\
\text { Secondary dose, n (\%) }\end{array}$ & $13(17.6 \%)$ & $20(27 \%)$ & 0.042 \\
\hline $\begin{array}{l}\text { Surfactant } \\
3 \text { dose, n (\%) }\end{array}$ & $2(2.7 \%)$ & $1(1.4 \%)$ & 0.042 \\
\hline
\end{tabular}


there was no significant difference between the two groups in terms of mean airway pressure at $72 \mathrm{~h}$ after birth.

\section{Discussion}

In recent years, studies have focused on non-invasive ventilation techniques to reduce the need for mechanical ventilation and its associated pulmonary complications [4]. Since 1970, noninvasive ventilation has been widely used in infants with CPAP. Studies have shown that CPAP reduces the need for oxygen dependence, respiratory rate and the need for mechanical ventilation $[21,22]$.

However, non-invasive BIPAP ventilation during the respiratory cycle produces two levels of CPAP with frequency and duration as determined by the physician. Therefore, in theory BIPAP should perform better in alveolar deployment, functional residual capacity (FRC) and improvement respiratory function than CPAP. However, this has not yet been validated in clinical studies, and some studies have not yet demonstrated a clear link between BPD and non-invasive ventilation [23-26]. In this context, the present study aimed to compare the two non-invasive ventilation methods of NDUOPAP and NCPAP among 148 preterm infants with respiratory distress syndrome aged 28 to 34 weeks. Because infants weighing less than $1000 \mathrm{~g}$ and under 28 weeks of gestation are usually intubated and undergo mechanical ventilation, they were not included in this study $[27,28]$.

In the present study, the need for endotracheal intubation in the first $72 \mathrm{~h}$ of birth was not significantly different between the two groups $(p=0.494)$, which is similar to the results of Gao et al. [29], Aguiar et al. [30] and Victor S et al. [31] However, in the study of Zhou et al. [12] and Kong et al. [18], the need for endotracheal intubation was significantly lower in the NDUOPAP group than in the NCPAP group.

There was no statistically significant difference between the NDUOPAP and NCPAP groups in the present study. However, since the number of treatment failures in this study was three in the NDUOPAP group and six in the NCPAP group, despite the nonsignificant statistical difference between the two groups, this difference was clinically remarkable, which requires further investigations with larger sample sizes.

In this study, the amounts of $\mathrm{PCO}_{2}$ one hour after treatment in the NDUOPAP and NCPAP groups were $44.06 \pm 4.11 \mathrm{mmHg}$ and $46.51 \pm 3.86 \mathrm{mmHg}$, respectively, which was statistically significant $(p=0.029)$, although this difference isn't clinically considerable. This finding is consistent with the study of Zhou et al. [12] and Kong et al. [18]. The reason for this may be the improvement of the minute ventilation caused by the use of the NDUOPAP method [12].
In the present study, arterial blood $\mathrm{PaO}_{2}$ levels were also compared one hour after treatment in the NDUOPAP and NCPAP neonates, which were $72.21 \pm 5.37$ $\mathrm{mmHg}$ and $67.01 \pm 6.57 \mathrm{mmHg}$, respectively, showing a significant difference between the two groups. This finding is also justified by the use of alveolar volume, flow and increased mean airway pressure (MAP) in patients treated with NDUOPAP [12, 32]. The findings of our study were similar to those of Zhou et al. [12] and Kong et al. [18].

In the present study, the mean duration of noninvasive ventilation between the NDUOPAP and NCPAP groups was $39.18 \pm 18.14 \mathrm{~h}$ and $50.12 \pm 23.83 \mathrm{~h}$, respectively, which were significantly different $(p=0.004)$. This could be due to improved use of alveoli and accelerated production of surfactant. This significant difference may be the result of improved blood gas exchange in the neonate treated with NDUOPAP [11]. These findings were in agreement with the results of Lista et al. [19] and Arora et al. [32]. In the study of Zhou et al., the duration of non-invasive ventilation was similar in both NDUOPAP and NCPAP groups [12]. Also, in the study of GAO et al., no significant difference was found in the duration of noninvasive ventilation between the three groups of NCPAP, BIPAP and SBIPAP [29].

The duration of oxygen therapy in our study in the two groups NDUOPAP and NCPAP was 75.48 and $107.45 \mathrm{~h}$, respectively, indicating a significant difference between the two groups $(p=0.034)$. This is also justified by improved alveolar deployment, improvement respiratory function and early respiratory system stability in patients treated under NDUOPAP treatment. These findings are consistent with those of Arora et al. [32] and Lista et al. [19].

The duration of hospitalization in the NDUOPAP and NCPAP groups was 495.88 and $668.08 \mathrm{~h}$, respectively. There was a statistically significant difference between the two groups $(P=0.002)$. The results were consistent with those of Lista et al. [19] and Arora et al. [32]. This may be due to lower duration of non-invasive ventilation and oxygen therapy and earlier stabilization of the patient's respiratory status.

The need for surfactant administration was also studied in both groups. The need for surfactant administration was significantly lower in NDUOPAP group $(p=0.042)$, which could be due to improved airway pressure and preventing alveolar collapse and thus reducing oxygen demand [33]. Alveolar stability during inhalation and exhalation may accelerate the production of surfactant and, on the other hand, achieve the ideal alveolar distribution of surfactant on alveolar surface. However, to prove this, separate studies are needed with larger sample sizes. In a study by Ricotta et al. in 2013, there was no 
significant difference between multiple doses of surfactant in the two groups of BiPAP and NIPPV [34].

In this study mortality was the same in both groups, probably because the number of treatment failure and prematurity complications were similar in both groups, which is similar to the studies of Arora et al. [32], Salvo et al. [35], and Gao et al. [29]. There was no significant difference between the two groups in terms of presence pneumothorax $(p=0.497)$, which is consistent with the results of Zhou et al. [12] and Lista et al. [19].

Bronchopulmonary dysplasia (BDP) was not significantly different between the two groups $(p=0.319)$. Many studies have investigated the incidence of PBD between different modes. Zhou et al. [12], Arora et al. [32] Rong et al. [36], and Lista et al. [19] obtained similar results.

The PDA $(P=1)$ and IVH $(P=0.1719)$ in both groups were similar, which was similar to findings of Zhou et al. [12]. Salvo's results [35] showed no significant difference in IVH and PDA rates between the CPAP, BiPAP and NSIPPV groups. There was also no significant difference in IVH rate between the two groups of BiPAP and CPAP in the study of Gao et al. [29]. Similar results were found in the study of Lista et al. [19] regarding IVH.
There was no significant difference between the two groups in the rate of apnea in the present study $(P=$ 0.366 ). This may be due to the low number of neonates with apnea and the lack of significance of this variable in the present study. Nursing reports on the severity of apnea are unreliable because existing devices cannot detect obstructive apnea or mixed apnea and can only record central apnea [37].

In our study, mean airway pressure was evaluated every $6 \mathrm{~h}$ in both modes. $P$-value up to $48 \mathrm{~h}$ was less than 0.001 and at $69 \mathrm{~h}$ it was $p<0.002$. However, at $72 \mathrm{~h}$, the $P$-value was equal to 0.101 , which may be due to separation of some patients from the device, thus decreasing the sample size (Table 3 ).

\section{Limitations}

Limitations of this study include limited sample size and exclusion of infants with gestational age less than 28 weeks in this study. A multicenter study is needed to further validate these findings.

\section{Conclusions}

In this study, NDUOPAP was compared to NCPAP and did not decrease the need for mechanical ventilation in

Table 3 Mean Airway Pressure difference during treatment in study groups

\begin{tabular}{|c|c|c|c|c|c|}
\hline & \multicolumn{2}{|c|}{ MAP(CM/H2O) \& Median } & \multirow[t]{2}{*}{ P-VALUE } & \multicolumn{2}{|c|}{ Patient Number } \\
\hline & NDUOPAP & NCPAP & & NDUOPAP & NCPAP \\
\hline \multirow[t]{2}{*}{ At admit time } & $6.89 \pm 0.76$ & $5.29 \pm 0.47$ & $<0.001$ & 74 & 74 \\
\hline & $6.85(1.30)$ & $5.10(0.70)$ & & & \\
\hline \multirow[t]{2}{*}{ After 6 Hour } & $6.65 \pm 1.06$ & $5.12 \pm 0.63$ & $<0.001$ & 74 & 73 \\
\hline & $6.50(1.13)$ & $5(0.4)$ & & & \\
\hline \multirow[t]{2}{*}{ After 12 Hour } & $6.07 \pm 1.03$ & $4.75 \pm 0.49$ & $<0.001$ & 72 & 71 \\
\hline & $6.25(1.17)$ & $4.90(0.50)$ & & & \\
\hline \multirow[t]{2}{*}{ After 18 Hour } & $5.63 \pm 1.41$ & $4.46 \pm 0.72$ & $<0.001$ & 72 & 71 \\
\hline & $5.95(2.40)$ & $4.80(1)$ & & & \\
\hline \multirow[t]{2}{*}{ After 24 Hour } & $5.11 \pm 1.20$ & $4.28 \pm 0.85$ & $<0.001$ & 67 & 71 \\
\hline & $5.30(2.2)$ & $4.70(1.60)$ & & & \\
\hline \multirow[t]{2}{*}{ After 30 Hour } & $5.17 \pm 1.12$ & $4.65 \pm 3.74$ & $<0.001$ & 48 & 58 \\
\hline & $5.30(2.22)$ & $4.10(1)$ & & & \\
\hline \multirow[t]{2}{*}{ After 36 Hour } & $4.77 \pm 1.07$ & $3.96 \pm 0.66$ & $<0.001$ & 43 & 52 \\
\hline & $4.2(1.5)$ & $4(0.9)$ & & & \\
\hline \multirow[t]{2}{*}{ After 42 Hour } & $4.64 \pm 1.02$ & $3.69 \pm 0.71$ & $<0.001$ & 40 & 27 \\
\hline & $4.1(1.55)$ & $3.6(0.9)$ & & & \\
\hline \multirow[t]{2}{*}{ After 48 Hour } & $4.67 \pm 1.10$ & $3.64 \pm 0.76$ & $<0.001$ & 26 & 42 \\
\hline & $4.10(1.65)$ & $3.25(1.10)$ & & & \\
\hline \multirow[t]{2}{*}{ After 60 Hour } & $4.43 \pm 0.92$ & $3.49 \pm 0.61$ & 0.002 & 10 & 25 \\
\hline & $4.20(1.35)$ & $3.20(1)$ & & & \\
\hline \multirow[t]{2}{*}{ After 72 Hour } & $3.88 \pm 0.53$ & $3.39 \pm 0.45$ & 0.101 & 5 & 17 \\
\hline & $4.10(085)$ & $3.20(0.90)$ & & & \\
\hline
\end{tabular}


the first $72 \mathrm{~h}$ of birth, but the duration of non-invasive ventilation, duration of oxygen requirement, and duration of hospitalization in the NDUOPAP group were lower. However, further studies are needed to evaluate the potential benefits of non-invasive ventilation, especially for vulnerable preterm infants or low Apgar infants.

\section{Abbreviations}

ABG: Arterial blood gas; BIPAP: Bilevel positive airway pressure; BPD: Bronchopulmonary dysplasia; DUOPAP: Duo positive airway pressure; HFNC: High flow nasal cannula; IVH: Intraventricular hemorrhage; MAP: Mean airway pressure; NCPAP: Nasal continuous positive airway pressure; NHFO: Nasal high frequency oscillation; NIPPV: Nasal intermittent positive ventilation; PDA: Patent ductus arteriosus; RDS: Respiratory distress syndrome

\section{Acknowledgements}

We would like to express our deepest appreciation to the participates and their parents. This paper is issued from the fellowship thesis of Neonatology. This work was financially supported by grant U-97089 from vice chancellor for Research Affairs of Ahvaz Jundishapur University of Medical Sciences.

\section{Authors' contributions}

MD: Conceptualization, Methodology, Supervision. MA: Data curation. AM: Writing- Original draft preparation: AM and MA: Visualization, Investigation. MRA: Reviewing and Editing. All authors have read and approved the manuscript.

\section{Funding}

Ahvaz Jundishapur University of Medical Sciences (U-97089).

\section{Availability of data and materials}

The datasets generated and analyzed during the current study are available from the corresponding author on reasonable request.

\section{Declarations}

\section{Ethics approval and consent to participate}

This study was approved by Ethical committee of The Ahvaz Jundishapur University of Medical Sciences (IR.AJUMS.REC.1397.365). Written informed consent was obtained from the legal parent of the neonate.

\section{Consent for publication}

Not applicable.

\section{Competing interests}

The authors declare that they have no competing interests.

Received: 30 September 2020 Accepted: 26 May 2021

Published online: 06 July 2021

\section{References}

1. Gnanaratnem J, Finer N. Neonatal acute repiratory failure. Curr opin pedicutr. 2000 Jun;12(13):227 - 32. https://doi.org/10.1097/00008480-2 00006000-00009.

2. Moya FR, Mazela J, Shore PM, et al. Prospective observational study of early respiratory management in preterm neonates less than 35 weeks of gestation. BMC Pediatr. 2019;19:147. https://doi.org/10.1186/s12887-019-151 8-3

3. Bhandari $V$. The potential of non-invasive ventilation to decrease BPD. Semin Perinatol. 2013;37:108-14. https://doi.org/10.1053/j.semperi.2013. 01.007

4. Blennow $M$, Bohlink K. Surfactant and noninvasive ventilation. neonatology. 2015;107(4):330. https://doi.org/10.1159/000381122. Epub 2015 Jun 5.

5. Reiterer F, Polin RA. Non -invasive ventilation in Preterm infants: a clinical Review. Int J Pediatr Neonat Care. 2016;2:118.

6. Schmölzer GM, Kumar M, Pichler G, Aziz K, O'Reilly M, Cheung PY. Noninvasive versus invasive respiratory support in preterm infants at birth: systematic review and meta-analysis. Bmj. 2013;347:1-8. https://doi.org/1 $0.1136 /$ bmj.f5980

7. Fischer HS, Buehrer C. Avoiding endotracheal ventilation to prevent bronchopulmonary dysplasia: a meta-analysis. Pediatrics. 2013;132(5):135160. https://doi.org/10.1542/peds.2013-1880.

8. Finer NN, Carlo WA, Walsh MC, Rich W, Gantz MG, Laptook AR and al, e Early CPAP versus surfactant in extremely preterm infants. New England J Med, 2010;362(21):1970-1979.https://doi.org/10.1056/NEJMoa0911783.

9. Göpel W, Kribs A, Ziegler A, Laux R, Hoehn T, Wieg C, Groneck P. Avoidance of mechanical ventilation by surfactant treatment of spontaneously breathing preterm infants (AMV): an open-label, randomised, controlled trial. Lancet. 2011;378(9803):1627-34. https://doi.org/10.1016/S0140-6736(11 60986-0.

10. Carlo WA. Should nasal high-frequency ventilation be used in preterm infants? Acta Paediatr. 2008;97(11):1484-5. https://doi.org/10.1111/j.1651-222 7.2008.01016.x.

11. Sadeghnia A, Barekateyn B, Badiei Z, Hosseini SM. Analysis and comparison of the effects of N-BiPAP and Bubble-CPAP in treatment of preterm newborns with the weight of below 1500 grams affiliated with respiratory distress syndrome: a randomised clinical trial. Adv Biomed Res. 2016. https:// doi.org/10.4103/2277-917174965

12. Zhou B, Zhai JF, Jiang HX, Liu Y, Jin B, Zhang YY, Wu JB. Usefulness of DuoPAP in the treatment of very low birth weight preterm infants with neonatal respiratory distress syndrome. Eur Rev Med Pharmacol Sci. 2015; 19(4):573-7.

13. Bahman-Bijari B, Malekiyan A, Niknafs P, Baneshi MR. Bubble-CPAP vs, Ventilatory-CPAP in preterm infants with respiratory distress. Iran J Pediatr. 2011 Jun;21(2):151-8. PMID: 23056781; PMCID: PMC3446163.

14. Wiswel TH, Srinivasan P, Continues positive air way perssure. In:Gold Smith JP, Karotkin EH(eds). Assisted ventilation of the Neonate. 3rd ed. Philadelphia: Sunders, 2003;127-143.

15. Dai MY, Zheng GF, Hao XQ, Liu S, Wu R. Silverman Anderson score applying in preterm infants with respiratory distress syndrome. Chin J Child Health Care, 2013;7. https://en.cnki.com.cn/Article en/CJFDTotal-ERTO201307027. htm.

16. Malakian A, Bashirnezhadkhabaz S, Aramesh MR, Dehdashtian M. Noninvasive high-frequency oscillatory ventilation versus nasal continuous positive airway pressure in preterm infants with respiratory distress syndrome: a randomized controlled trial. J Matern Fetal Neonatal Med. 2020 Aug;33(15):2601-7. doi: 10 1080/14767058.2018.1555810. Epub 2019 Mar 8. PMID: 30513030

17. Stevens TP, Blennow M, Myers EH, Soll R. Early surfactant administration with brief ventilation vs. selective surfactant and continued mechanical ventilation for preterm infants with or at risk for respiratory distress syndrome. Cochrane Database Syst Rev. 2007;4:CD003063. https://doi.org/1 $0.1002 / 14651858 C D 003063 p u b 3$

18. Kong LK, Kong XY, Li LH, Dong JY, Shang MX, Chi JH, Huang RX, Zheng Y, Ma JE, Chen XC, Wang Y, Cai N, Feng ZC. Comparative study on application of Duo positive airway pressure and continuous positive airway pressure in preterm neonates with respiratory distress syndrome. Zhongguo dang dai er ke za zhi = Chin J Contemp Pediatr. 2012;14(12):888-92.

19. Lista G, Castoldi F, Fontana P, Daniele I, Cavigioli F, Rossi S, Diego Mancuso D, Reali R. Nasal continuous positive airway pressure (CPAP) versus bi-level nasal CPAP in preterm babies with respiratory distress syndrome: a randomised control trial. Arch Dis Childhood-Fetal Neonatal Edition. 2010; 95(2):85-9. https://doi.org/10.1136/adc.2009.169219.

20. Mrinal S, MariJ-sankar $P$, et al. Preterm VLBW Neonates with early onset respiratory distress. J Trop Pediatr. 2011;57:274-9.

21. Kamper J, Wulff K, Larsen C, Lindequist S. Early treatment with nasal continuous positive airway pressure in very low-birth-weight infants. Acta Paediatr. 1993;82(2):193-7. https:/doi.org/10.1111/j.1651-2227.1993.tb12637.x.

22. Mazzella M, Bellini C, Calevo MG, Campone F, Massocco D, Mezzano P, Zullinoa E, Scopesia F, Arionia C, Bonaccia W, Serra G. A randomised control study comparing the infant flow driver with nasal continuous positive airway pressure in preterm infants. Arch Dis Childhood-Fetal Neonatal Edition. 2001;85(2):86-90. https://doi.org/10.1136/fn.85.2.F86.

23. Thomson MA. Continuous positive airway pressure and surfactant; combined data from animal experiments and clinical trials. Neonatology. 2002:81(Suppl. 1):16-9. https://doi.org/10.1159/000056766.

24. Morley CJ, Davis PG, Doyle LW, Brion LP, Hascoet JM, Carlin JB. Nasal Cpap or intubation at birth for very preterm infants. N Engl J Med. 2008;358(7): 700-8. 
25. Di Fiore JM, Walsh M, Wrage L, Rich W, Finer N, Carlo WA, Martin RJ SUPPORT Study Group of Eunice Kennedy Shriver National Institute of Child Health and Human Development Neonatal Research Network. Low oxygen saturation target range is associated with increased incidence of intermittent hypoxemia. J Pediatr. 2012;161(6):1047-52.

26. Thomson MA. Early nasal continuous positive airways pressure (nCPAP) with prophylactic surfactant for neonates at risk of RDS. The IFDAS multi-centre randomised trial. In Pediatric Research 2002 (Vol. 51, No. 4, pp. 379A-379A). Baltimore: Int Pediatric Research Foundation, Inc.

27. Dargaville PA, Gerber A, Johansson S, De Paoli AG, Kamlin COF, Orsini F, Davis PG. Incidence and outcome of CPAP failure in preterm infants. Pediatrics. 2016;138(1):1-12. https://doi.org/10.1542/peds.2015-3985.

28. Gonçalves-Ferri WA, Martinez FE. Nasal Cpap in the delivery room for new born with extremely low birth weight in a hospital in a developing country. Braz J Med Biol Res. 2013:46(10):892-6 -431 X2013 2849.

29. Gao X, Yang B, Hei M, Cui X, Wang J, Zhou G, Qu S. [Application of three kinds of non-invasive positive pressure ventilation as a primary mode of ventilation in premature infants with respiratory distress syndrome: a randomized controlled trial]. Zhonghua Er Ke Za Zhi. 2014;52(1):34-40 Chinese. PMID: 24680406

30. Aguiar T, Macedo I, Voutsen O, Silva P, Nona J, Araujo C. Nasal bilevel versus continuous positive airway pressure in preterm infants: a randomized controlled trial. J Clin Trials. 2015;5(221):2167 - 0870. https://doi.org/10.41 72/2167-0870.1000221

31. Victor S, Roberts SA, Mitchell S, Aziz H, Lavender T; Extubate Trial Group. Biphasic positive airway pressure or continuous positive airway pressure: a randomized trial. Pediatrics. 2016;138(2):e20154095. https://doi.org/10.1542/ peds.2015-4095.

32. Arora V, Gediya SG, Balai SS. Nasal CPAP vs Bi-level Nasal CPAP in preterms with RDS: a randomized control study. Int J Contemp Pediatr. 2017;4(3):9758. https://doi.org/10.18203/2349-3291.ijcp20171710

33. Donn SM, Manual of neonatal respiratory care. S. K. Sinha, editor. Berlin Heidelberg New York:Springer., 2012;93-98.

34. Ricotti A, Salvo V, Zimmermann LJ, Gavilanes AW, Barberi I, Lista G, Colivicchi M, Temporini F, Gazzolo D. N-SIPPV versus bi-level N-CPAP for early treatment of respiratory distress syndrome in preterm infants. Matern-Fetal Neonatal Med. 2013;26(13):1346-51. https://doi.org/10.3109/14 767058.2013.784255.

35. Salvo V, Lista G, Lupo E, Ricotti A, Zimmermann LI, Gavilanes AWD, Gitto E, Colivicchi M, Ferraù V, Gazzolo D. Comparison of three non-invasive ventilation strategies (NSIPPV/BiPAP/NCPAP) for RDS in VLBW infants. J Matern-Fetal Neonatal Med. 2018;31(21):2832-8. https://doi.org/10.1080/14 767058.2017.1357693.

36. Rong ZH, Li WB, Liu W, Cai BH, Wang J, Yang M, Wei L, Chang LW. Nasal bilevel positive airway pressure (BiPAP) versus nasal continuous positive airway pressure (CPAP) in preterm infants $\leq 32$ weeks: a retrospective cohort study. J Paediatr Child Health. 2016;52(5):493-8. https://doi.org/1 $0.1111 /$ jpc. 13175.

37. Pillekamp F, Hermann C, Keller T, Von Gontard A, Kribs A, Roth B. Factors influencing apnea and bradycardia of prematurity-implications for neurodevelopment. Neonatology. 2007;91(3):155-61. https://doi.org/10.11 $59 / 000097446$

\section{Publisher's Note}

Springer Nature remains neutral with regard to jurisdictional claims in published maps and institutional affiliations.

Ready to submit your research? Choose BMC and benefit from:

- fast, convenient online submission

- thorough peer review by experienced researchers in your field

- rapid publication on acceptance

- support for research data, including large and complex data types

- gold Open Access which fosters wider collaboration and increased citations

- maximum visibility for your research: over $100 \mathrm{M}$ website views per year

At $\mathrm{BMC}$, research is always in progress.

Learn more biomedcentral.com/submissions 